\title{
Gastroesophageal Reflux after Peroral Endoscopic Myotomy: Myth or Reality?
}

\author{
Amol Bapaye ${ }^{1 \odot}$ Ashish Gandhi ${ }^{10}$ Jay Bapaye ${ }^{2 \odot}$ \\ ${ }^{1}$ Shivanand Desai Center for Digestive Disorders, Deenanath \\ Mangeshkar Hospital and Research Center, Pune, India \\ 2 Department of Internal Medicine, Rochester General Hospital, \\ Rochester, New York, United States
}

\begin{abstract}
Address for correspondence Amol Bapaye, MD (MS), FASGE, FJGES, FSGEI, Shivanand Desai Center for Digestive Disorders, Deenanath Mangeshkar Hospital and Research Center, Erandwane, Pune 411004, Maharashtra, India (e-mail: amolbapaye@gmail.com).
\end{abstract}

J Digest Endosc 2021;12:202-213.

\begin{abstract}
Keywords

- peroral endoscopic myotomy

- gastroesophageal reflux

- post-POEM GER

- gastrointestinal reflux disease

Peroral endoscopic myotomy (POEM) is an accepted treatment for achalasia cardia (AC), and results are comparable to those of laparoscopic Heller myotomy (LHM). In recent years, several reports have confirmed higher incidence of gastroesophageal reflux (GER) following POEM. This review evaluates the current evidence regarding post-POEM GER, critically examines the potential contributing factors responsible for GER, limitations of the current available functional testing, and precautions and preventive measures, and provides future directions for research. Factors conclusively contributing to increased post-POEM GER include injury to the sling fibers of the lower esophageal sphincter, length of gastric myotomy $>2 \mathrm{~cm}$, and others. Historically, these same factors have been implicated for development of GER after surgical (laparoscopic) myotomy. Although less invasive, optimal technique of POEM may be important to control post-POEM GER. Most post-POEM GER occurs during the immediate post-POEM period, is mild, and is easily treatable using proton-pump inhibitors. GER incidence plateaus at 2 years and is comparable to that after LHM. Patients should therefore be prescribed proton-pump inhibitors for at least 2 years. Antireflux procedures (ARPs) are infrequently required in these patients as the incidence of refractory GER is low. Novel ARPs have been recently described and are currently under evaluation. Conclusive diagnosis of GER is a clinical challenge. Most patients are asymptomatic, and GER is diagnosed only on abnormal esophageal acid exposure (EAE). Studies have demonstrated that current measures to diagnose GER are inadequate, inaccurate, and cannot differentiate between true GER and abnormal EAE due to food fermentation in the distal esophagus. The Lyon Consensus criteria should be implemented for confirmation of diagnosis of GER. Finally, the review recommends an evidence-based clinical algorithm for evaluation and management of post-POEM GER and provides guidelines for future research in this field.
\end{abstract}

DOI https://doi.org/ 10.1055/s-0041-1740489. ISSN 0976-5042. (c) 2022. Society of Gastrointestinal Endoscopy of India. All rights reserved.

This is an open access article published by Thieme under the terms of the Creative Commons Attribution-NonDerivative-NonCommercial-License, permitting copying and reproduction so long as the original work is given appropriate credit. Contents may not be used for commercial purposes, or adapted, remixed, transformed or built upon. (https://creativecommons.org/ licenses/by-nc-nd/4.0/)

Thieme Medical and Scientific Publishers Pvt. Ltd., A-12, 2nd Floor, Sector 2, Noida-201301 UP, India 


\section{Introduction}

Achalasia cardia (AC) is a motility disorder of the esophagus characterized by nonrelaxation of the lower esophageal sphincter (LES) to wet swallows and loss of esophageal body peristalsis. Treatment options for AC are primarily palliative and are targeted toward disruption of the LES musculature, thereby relieving spasm and permitting oral diet.

Nonpharmacological treatment options for AC include endoscopic balloon dilatation (EBD), laparoscopic Heller myotomy (LHM), and, more recently, peroral endoscopic myotomy (POEM). POEM was first reported by Inoue et al in $2010 .^{1}$ POEM is based on the principle of third-space endoscopy and utilizes the mucosal flap valve principle to perform an LES myotomy via a submucosal tunnel. ${ }^{2}$ It has quickly emerged as an effective and popular treatment option. POEM has demonstrated excellent success rates above $90 \%$ in several large studies, meta-analyses, and systematic reviews. ${ }^{3-17}$

Results of POEM are superior to those of single-session EBD and are comparable to those of LHM. ${ }^{18}$ Early studies on POEM reported modest postprocedure gastrointestinal reflux disease (GERD) in 12 to $21 \%$ of patients, ${ }^{3,4,8}$ possibly due to the limited follow-up included. Recent studies have focused on post-POEM GERD in greater detail and have reported an alarming 40 to $60 \%$ incidence of post-POEM GERD, ${ }^{9,10,13,17-23}$ so much so that it prompted an editorial addressing this concern. ${ }^{24}$

Given the fact that all three modalities are primarily directed toward LES relaxation, some element of increased GER may be considered as a natural outcome of these therapies. However, the frequency, severity, and pathological nature of GER often differ depending on the treatment modality and need to be taken into consideration while choosing the therapy.

This review focuses on post-POEM GER and critically evaluates the current evidence, discusses the potential contributing factors responsible for GER, limitations of the current available functional testing, and precautions and preventive measures, and provides future directions for research in this field.

\section{The Issue of Post-POEM GER}

Most early studies on POEM reported modest postprocedure GERD in 12 to $21 \%$ of patients, ${ }^{3,4,8}$ possibly due to the limited follow-up included. However, recent data show otherwise (-Table 1). Werner et al, in their randomized study, reported GER in $57 \%$ of patients undergoing POEM versus $20 \%$ in those undergoing LHM. ${ }^{16}$ Similar incidence has been reported in other studies. ${ }^{9,10,13,17,19-23,25-27}$ A large single-center study of over 200 consecutive patients reported a high DeMeester score ( $>14.72$ ), endoscopy-confirmed reflux esophagitis, and symptomatic GERD in $47.9,41.9$, and $29.3 \%$ of patients, respectively. ${ }^{26}$ In an extensive meta-analysis comparing LHM to POEM that included 74 studies involving more than 7,000 patients, it was found that patients undergoing
POEM were more likely to develop GERD symptoms (odds ratio [OR], 1.69; 95\% confidence interval [CI], 1.33-2.14; $p<0.0001$ ), erosive esophagitis (OR, 9.31; 95\% Cl, 4.7118.85; $p<0.0001$ ), and abnormal esophageal acid exposure (EAE) (OR, 4.30; 95\% CI, 2.96-6.27; $p<0.0001$ ) as compared with those undergoing LHM. ${ }^{20}$ Another meta-analysis evaluating 17 and 28 studies with 1,542 and 2,581 patients of POEM and LHM, respectively, reported higher abnormal EAE (pooled rate estimate: 39 vs. 16.8\%) and esophagitis (29.4 vs. $7.6 \%$ ) for POEM and LHM, respectively. ${ }^{25}$ GERD is significantly more frequent after POEM as compared with both pneumatic dilatation and LHM. ${ }^{18,20,22,25,28,29}$ POEM has therefore been criticized by surgical experts. ${ }^{30}$

Most studies have reported significant discrepancy between pH studies, endoscopy, and GER symptoms. Also, in several studies, GER reporting does not follow a consistent protocol ( - Table 2) ${ }^{31,32}$ GER has been variably reported in studies based on $\mathrm{pH}$ studies, endoscopy, symptoms, or a combination of all or some of these parameters. Notably, despite a high incidence of abnormal EAE, symptomatic GER and erosive esophagitis have been found to be much less frequent. ${ }^{14,26}$ Furthermore, most post-POEM GER is mild. In the study by Kumbhari et al, despite a very high rate of abnormal EAE (57.8\%), erosive esophagitis was identified in $23.2 \%$ patients and severe grade C/D esophagitis was present in only $5.6 \%{ }^{13}$ Werner et al reported $57 \%$ post-POEM GER at 3 months based on $\mathrm{pH}$ and endoscopy findings but only 5.6\% had severe esophagitis. In addition, at 2-year follow-up, incidence of severe GER was comparable in both arms. ${ }^{16}$ In a multicenter Japanese study of more than 1,300 patients, although GER was documented in $63 \%$ of patients on $\mathrm{pH}$ studies, symptomatic GER was much less frequent (14.8\%). Severe grade C/D esophagitis was seen in only $6.2 \% .{ }^{17} \mathrm{~A}$ subsequent prospective study of 233 patients by the same group reported the incidence of post-POEM GER, symptoms, and severe GER as 54.2, 14.7, and 5.6\%, respectively, at 1-year follow-up. ${ }^{33}$ Another study comparing POEM to LHM reported that although symptomatic GERD was not significantly higher after POEM (28 vs. $14.9 \%, p=0.38$ ), abnormal EAE was significantly more frequent (48.4 vs. $13.6 \%$, $p<0.001) .{ }^{28}$ Nabi et al reported high DeMeester scores and endoscopic reflux esophagitis in 47.9 and $41.9 \%$ of patients, respectively, but only $29.3 \%$ of patients were symptomatic for GER. ${ }^{26}$ In the meta-analysis by Repici et al, ${ }^{25}$ GER was reported in $39 \%$ of patients based on $\mathrm{pH}$ studies, whereas $29.4 \%$ of patients had endoscopic esophagitis, $19 \%$ were symptomatic, and only $4.47 \%$ had severe GER. A study evaluating incidence of post-POEM GERD in 68 patients over long term demonstrated that although $50 \%$ of patients reported GERD at 12 months, it was mild in most, no GERDrelated complications were noted in the 5-year follow-up post POEM, and $95 \%$ of patients were effectively controlled with proton-pump inhibitors (PPI). ${ }^{34}$

The above-mentioned studies suggest a poor correlation between abnormal EAE, endoscopic evidence of esophagitis, and GER symptoms. Also, although abnormal acid reflux may be higher after POEM, post-POEM GER is mostly mild and nonerosive. Nevertheless, the true significance of this 
Table 1 Incidence of reported GER in selected POEM studies

\begin{tabular}{|c|c|c|c|c|}
\hline Author (year) & Study design & $N$ & Follow-up (mo) & Incidence of GER (\%) \\
\hline von Renteln et al $(2011)^{3}$ & SC, pros, single arm & 16 & 3 & 0 \\
\hline Stavropoulos et al (2013) & MC, retro, single arm & 841 & 9.3 & 12 \\
\hline Sharata et al $(2014)^{7}$ & SC, pros, single arm & 100 & 16 & 38 \\
\hline \multirow[t]{2}{*}{ Inoue et al $(2015)^{8}$} & \multirow[t]{2}{*}{ SC, pros, single arm } & \multirow[t]{2}{*}{500} & Short (2 mo) & $16.8(2 \mathrm{mo})$ \\
\hline & & & Long (3 y) & $21.3(3 \mathrm{y})$ \\
\hline Familiari et al $(2016)^{9}$ & SC, retro, single arm & 103 & 24 & 50.5 \\
\hline Hungness et al (2016) ${ }^{10}$ & SC, retro, single arm & 115 & 28 & 40 \\
\hline \multirow[t]{2}{*}{ Repici et al $(2018)^{25}$} & \multirow{2}{*}{$\begin{array}{l}\text { Comparative POEM vs. } \\
\text { LHM, SRM }\end{array}$} & POEM: 1,542 & - & POEM: 39 \\
\hline & & LHM: 2581 & - & LHM: 16.8 \\
\hline Kumbhari et al (2017) ${ }^{13}$ & $\mathrm{MC}, \mathrm{CC}$ & 282 & 12 & 57.8 \\
\hline Martinek et al $(2018)^{21}$ & SC, pros, single arm & 133 & 24 & $\begin{array}{l}3 \text { mo: } 41.5 \\
12 \text { mo: } 29.7 \text { (reflux symptoms) } \\
3 \text { mo: } 37.6 \text { (mild reflux } \\
\text { esophagitis); } 41.5 \text { (pathological } \\
\text { GER) }\end{array}$ \\
\hline \multirow[t]{2}{*}{ Teitelbaum et al $(2018)^{19}$} & \multirow[t]{2}{*}{ SC, retro, single arm } & \multirow[t]{2}{*}{29} & \multirow[t]{2}{*}{65} & $39(6 \mathrm{mo})$ \\
\hline & & & & $13(5 \mathrm{y})$ \\
\hline \multirow[t]{2}{*}{ Schlottmann et al $(2018)^{20}$} & \multirow{2}{*}{$\begin{array}{l}\text { Comparative POEM vs. } \\
\text { LHM, SRM }\end{array}$} & POEM: 1,958 & & POEM: 47.5 \\
\hline & & LHM: 5,834 & & LHM: 11.1 \\
\hline Werner et al $(2019)^{16}$ & $\begin{array}{l}\text { MC, RCT, POEM vs. } \\
\mathrm{LHM}+\mathrm{F}\end{array}$ & $\begin{array}{l}\text { POEM: } 112 \\
\text { LHM: } 109\end{array}$ & 24 & $\begin{array}{l}3 \text { mo: } \\
\text { POEM: } 57 \\
\text { LHM: } 20 \\
2 \text { y: } \\
\text { POEM: } 44 \\
\text { LHM: } 29\end{array}$ \\
\hline Shiwaku et al $(2020)^{17}$ & MC, retro, single arm & 1,346 & 12 & 63 \\
\hline Aiolfi et al $(2019)^{22}$ & $\begin{array}{l}\text { Comparative POEM, } \\
\text { LHM, PD, SRM }\end{array}$ & $\begin{array}{l}N=4,407 \\
\text { LHM: } 50.4 \% \\
\text { PD: } 42.8 \% \\
\text { POEM: } 6.8 \%\end{array}$ & - & $\begin{array}{l}\mathrm{POEM}>\mathrm{LHM}(\mathrm{RR}=1.75 ; 95 \% \\
\left.\mathrm{Cl}=1.35-2.03 ; I^{2}=6.3 \%\right) \\
\mathrm{POEM}>\mathrm{PD}(\mathrm{RR}=1.36 ; 95 \% \\
\mathrm{Cl}=1.18-1.68)\end{array}$ \\
\hline Arevalo et al $(2020)^{23}$ & SC, retro, single arm & 46 & 12 & 41.7 \\
\hline Nabi et al $(2020)^{26}$ & SC, retro, single arm & 209 & 3 & $\begin{array}{l}3 \mathrm{mo}(n=167): 47.9 \\
1 \text { y }(n=106): 37.6\end{array}$ \\
\hline Modayil et al $(2021)^{76}$ & SC, retro, single arm & 610 & 30 & $4 \mathrm{mo}: 57.1$ \\
\hline
\end{tabular}

Abbreviations: CC, case-controlled; Cl, confidence interval; GER, gastroesophageal reflux; LHM, laparoscopic Heller myotomy; LHM + F, laparoscopic Heller myotomy with fundoplication; MC, multicenter; PD, pneumatic dilatation; POEM, peroral endoscopic myotomy; pros, prospective; RCT, randomized controlled study; retro, retrospective; RR, relative risk; SC, single center; SRM, systematic review and meta-analysis.

abnormal acid reflux may not be immediately evident and therefore long-term follow-up is recommended to evaluate for GER as well as for cancer surveillance, although currently there is no consensus regarding the frequency of these follow-up examinations. ${ }^{35}$

What could be the potential reasons for this increased GER after POEM? To understand the reasons behind this discrepancy, let us review the anatomical basis of reflux and the evolution of AC treatment over the past 100 years.

\section{Anatomical Basis for Post-AC Therapy GER}

All therapies for AC are designed to weaken or disrupt the LES. Certain amount of resultant GER is therefore expected to be a natural occurrence of all these therapies. Anatomically, two factors are considered crucial to maintain the competency of the LES: (1) the oblique sling muscle fibers of the LES, which are a continuation of the circular muscle fibers of the esophagus (-Fig. 1), and (2) integrity of the phrenoesophageal ligament, which is a membranous ligament fixing the abdominal part of the esophagus to the diaphragm (-Fig. 2). It is proposed that division of the sling fibers can prevent effective closure of the LES during episodes of increased abdominal pressure, whereas division of the phrenoesophageal ligament is thought to be integral to prevent upward migration of the LES and is therefore important to maintain the angle of His. ${ }^{36,37}$ An LES myotomy can adversely affect one or both of these natural barriers of GER. 
Post-POEM GER Bapaye et al. 205

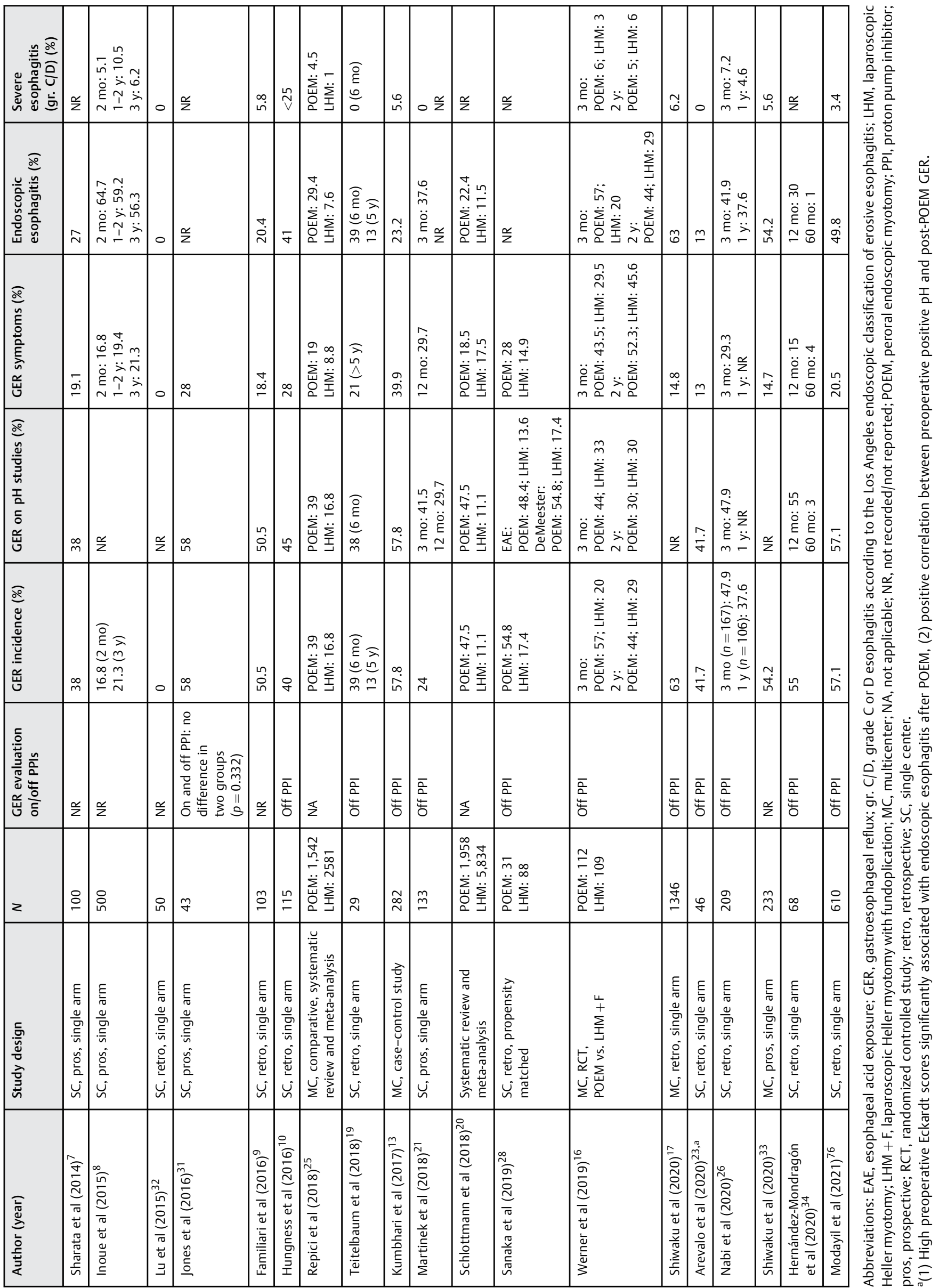




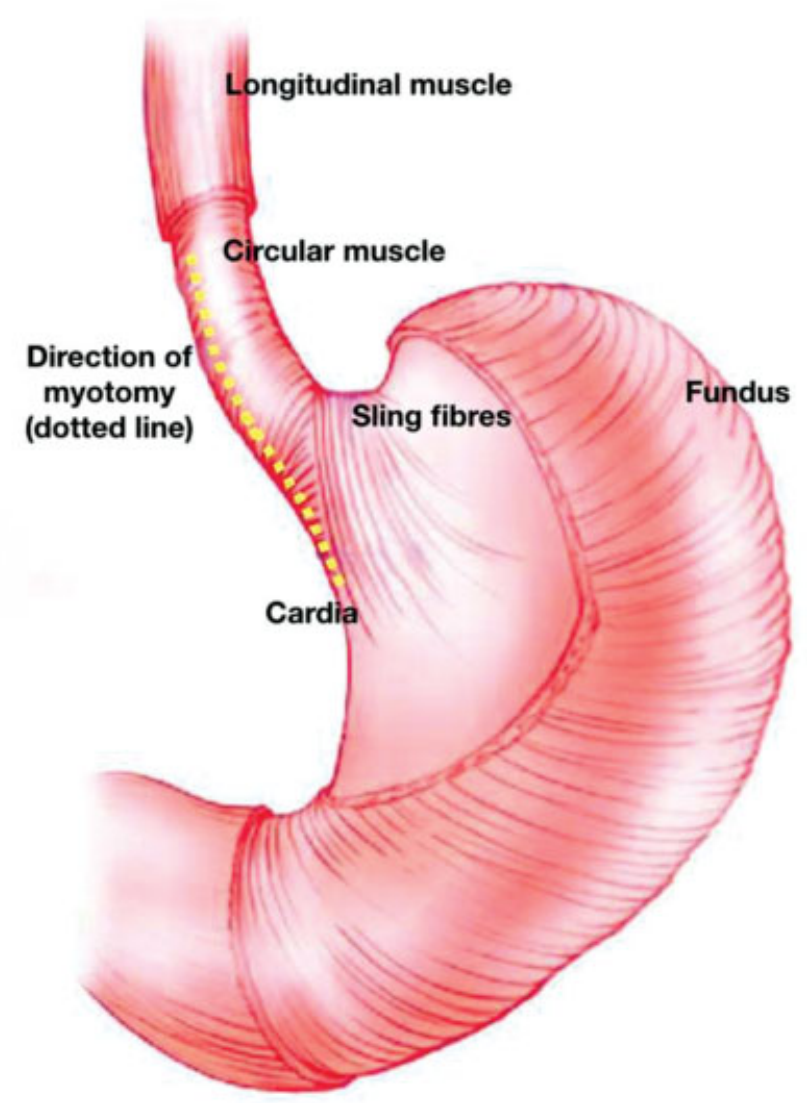

Fig. 1 Location of the sling fibers of the gastroesophageal sphincter and the recommended direction of myotomy during POEM.

\section{Historical Evolution of Heller Myotomy and the Controversy regarding Additional Antireflux Procedure}

In 1913, Ernst Heller first described a double-sided myotomy for AC using a thoracic approach. ${ }^{38}$ This was later modified by Zaaijer to a single-sided thoracic myotomy in $1923 .{ }^{39}$ Fundoplication did not form an integral part of these procedures initially. During the 1950s, an abdominal approach for myotomy was described and was soon preferred due to the reduced perioperative morbidity. GER was more frequently observed when the myotomy was performed by an abdominal approach as compared with the thoracic route. What was the reason for this difference? Division of the phrenoesophageal ligament, an integral protective antireflux mechanism of the LES, was inevitable while performing an abdominal myotomy. ${ }^{36,37}$ To control or prevent this GER, Dor in 1962 first reported an anterior partial fundoplication added to an abdominal Heller myotomy. ${ }^{40,41}$ A year later, Toupet reported a posterior partial fundoplication as an alternative. ${ }^{40,41}$ Subsequently, it was recommended to add fundoplication whenever the abdominal approach was used to perform myotomy, although the scientific basis behind such an approach was questioned and criticized by several authors at that time. To quote from the landmark review by Andreollo and Earlam, "additional anti-reflux procedures are only needed to compensate for an incorrectly done myotomy or are unnecessary." ${ }^{37}$

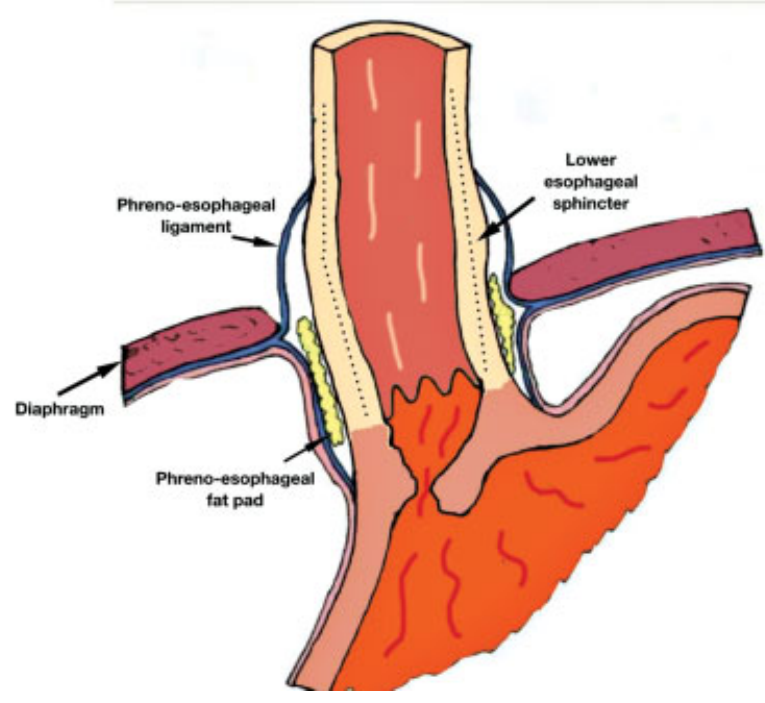

Fig. 2 Anatomical location of the phrenoesophageal ligament and its relevance as an antireflux barrier.

Preservation of the sling fibers has been identified as a protective mechanism against GER during the surgical era. Direction of myotomy was recommended to be toward the right on the lesser curve so as to preserve this important anatomical barrier. ${ }^{36}$ Extended length of the gastric myotomy was another factor identified to be contributing to postoperative GER, and this length was recommended to be maintained between 0.5 and $2 \mathrm{~cm}$ for optimum effect. ${ }^{36,37}$

With the advent of LHM, which employed the abdominal approach, adding fundoplication to LHM $(\mathrm{LHM}+\mathrm{F})$ became a norm. ${ }^{41}$ GER has been reported in up to $47.6 \%$ of patients after LHM but has been shown to reduce to 9 to $23 \%$ if fundoplication is added after LHM. $^{42,43}$

Post-LHM + F outcomes have not been consistent, however. Rawlings et al reported GER in 21 to $42 \%$ of patients post-LHM with fundoplication. ${ }^{44}$ Boeckxstaens et al reported increasing GER incidence during follow-up (23\% at 1 year vs. $34 \%$ at 4 years).$^{45}$ Long-term follow-up at more than 10 years post-LHM has demonstrated gradual clinical deterioration in esophageal function, predominantly as a result of pathological acid reflux ( $28 \%$ at $>10$ years and $53 \%$ at $>20$ years). Long-term failures have been reported in $22 \%$, predominantly due to GER, and short- or long-segment Barrett's has been reported in up to 13\% of patients. ${ }^{46}$ Similar results have been reported by other authors. ${ }^{47}$ Therefore, the controversy regarding routine versus selective fundoplication continues. Simić et al demonstrated that the extent of hiatal dissection (HD) rather than fundoplication was responsible for post-LHM GER. They compared three patient groups: complete HD and fundoplication; limited HD and fundoplication; and limited HD without fundoplication. The group with complete HD reported 23\% GER as compared with 8.5 and $9.1 \%$ in the other two groups. The authors concluded that division of the phrenoesophageal ligament during complete HD was possibly responsible for these observations. ${ }^{48}$

What has changed with the advent of POEM? POEM is an endoscopic surgical procedure that follows the principles of surgical myotomy. Since POEM is an endoscopic procedure, 
there is no HD or division of the phrenoesophageal ligament. Incidence of GER was therefore expected to be low as compared with other approaches. However, recent studies have reported high incidence of GER following POEM. Let us try to find answers to this clinical dilemma.

\section{POEM: An Evolving Procedure}

The first human case of POEM was performed in 2008 and the first case series was published in $2010 .^{1}$ Since then, several thousands of POEMs have been performed worldwide. Most manuscripts in the first 5 years have focused on efficacy, safety, and technique. Dysphagia relief has been the standard benchmark to define success and absence of intraprocedural adverse events (AEs) the measure of safety.

Post-POEM GER was being increasingly reported in later studies after 2015 when long-term outcomes of patients were evaluated. It is important to remember that most procedures in these studies had been performed earlier, some possibly as part of a learning curve. Given this fact, one could hypothesize that early POEMs employed a generous gastric myotomy to ensure good relief of dysphagia and minimize recurrence, especially as these procedures were being critically compared with the standard-of-care LHM $+\mathrm{F}$.

\section{Contributing Factors and Prevention of Post- POEM GER}

Two factors have now been conclusively proven to contribute to occurrence of post-POEM GER: (1) gastric length of myotomy more than $2 \mathrm{~cm}^{29,49}$ and (2) division of the sling fibers of the LES. ${ }^{17,49}$ We have seen that gastric length of myotomy has always been a contentious issue even with surgical myotomy, with longer myotomy being associated with increased incidence of GER. ${ }^{41}$ Especially, a posterior gastric myotomy more than $4 \mathrm{~cm}$ has been shown to significantly increase the incidence of post-POEM GER. ${ }^{17}$ Inoue et al, in their consensus statement on post-POEM GER, recommend gastric myotomy less than $2 \mathrm{~cm}$ as a potential preventive measure against GER (level of evidence: D). ${ }^{49}$ Double-endoscope technique has been recommended to accurately estimate the length of gastric myotomy (strength of recommendation: 1 ; level of evidence: D) ${ }^{49-51}$ This same recommendation has been echoed by other published guidelines. ${ }^{52,53}$ Another prospective study reported that gastric myotomy length affects the severity but not the rate of post-POEM GER and that $2.5 \mathrm{~cm}$ is the outer limit of gastric myotomy length beyond which GER could be more frequent. $^{54}$

The sling fibers of the LES are an integral part of the antireflux mechanism of the LES. Way back in 1965, Ellis and Cole reported on the importance of preservation of the gastric sling fibers during surgical myotomy. ${ }^{36}$ Irrespective of the surgical or endoscopic approach to myotomy, the basic anatomical principles do not change. The sling fibers are commonly encountered during posterior POEM and are recommended to be preserved to reduce the incidence of post-POEM GER. ${ }^{49}$ Tanaka et al have demonstrated a simple technique to identify and preserve the sling fibers during posterior POEM, as well as to demonstrate the adequacy of gastric length of myotomy. ${ }^{55,56}$ They identified the consistent presence of two sets of penetrating vessels at the gastroesophageal junction (GEJ) in 91\% of patients undergoing posterior POEM. These vessels are situated at the boundary of the oblique sling fibers and the circular muscle fibers. Performing myotomy to the right of these vessels in the direction of the lesser curve prevents injury to the sling fibers and has been shown to reduce post-POEM GER. ${ }^{55}$ Furthermore, the study recommends that the optimum length of gastric myotomy should be up to the second set of penetrating vessels as it corresponds to the recommended length of less than $2 \mathrm{~cm}^{56}$ Stavropoulos et al have reported encouraging results with an "antireflux POEM," wherein a 2-cm gastric myotomy is performed at the 2 o'clock position, thereby completely avoiding the sling fibers. ${ }^{57}$ In a casecontrol study published in abstract form, they reported lower proportion of positive $\mathrm{pH}$ studies (43 vs. $75 \%$, $p<0.001$ ), total acid exposure (4.1 vs. $10 \%, p<0.0001$ ), number of refluxes (29 vs. 53, $p=0.005$ ), and less GERD symptoms ( 7 vs. $22 \%$ of patients with $<2$ episodes/week) in patients subjected to the "antireflux" POEM as compared with a conventional POEM. These observations require validation in further studies.

Length of esophageal myotomy has been recently proposed as a factor contributing to post-POEM GER on univariate analysis, although this could not be confirmed on multivariate analysis. ${ }^{33}$ This is possibly because a longer esophageal myotomy can impair distal esophageal acid clearance from an already hypotonic aperistaltic esophagus. Posterior myotomy as compared with anterior myotomy was earlier implicated as a potential risk factor for GER-based higher EAE demonstrated in patients undergoing posterior myotomy, although incidence of esophagitis was comparable. ${ }^{58}$ This claim has later been refuted by a subsequent study from the same group and another randomized trial, both demonstrating no difference in GER rates for patients treated by either approach. ${ }^{26,59}$ Clinically relevant GER was reported to be more frequent in patients undergoing a full-thickness myotomy as compared with a selective circular myotomy, although GER symptoms, EAE, and esophagitis were comparable in both groups. ${ }^{60}$ This fact has not been substantiated in other studies. ${ }^{61,62}$

The functional lumen imaging probe (FLIP) has recently been evaluated as a tool to predict post-POEM GER. Teitelbaum et al reported that a distensibility index (DI) $<6 \mathrm{~mm}^{2}$ / $\mathrm{mm} \mathrm{Hg}$ was predictive of lower risk for GER. ${ }^{63}$ FLIP has also been used to estimate the optimal length of gastric myotomy, and has shown that extending the gastric myotomy to more than $2 \mathrm{~cm}$ does not have any beneficial effect on the DI. ${ }^{64}$ FLIP could therefore be recommended as a tool to estimate the optimum length of gastric myotomy while performing POEM. Patients with pathological EAE after POEM are reported to have significantly higher EGJ DI irrespective of reflux symptoms, indicating that LES laxity post-POEM is the likely contributing factor for GER in these patients. ${ }^{65}$

Interestingly, a study by Sanaka et $\mathrm{al}^{28}$ demonstrated that prior LHM + F had no impact on post-POEM abnormal EAE. 
Does that imply that fundoplication may not safeguard against post-POEM GERD? Conclusive information regarding this point is presently lacking. However, these observations do imply that functional integrity of the LES may not be the sole contributing factor responsible for post-POEM GER.

\section{The Problem of GER Overdiagnosis in Patients with Achalasia}

Can every post-POEM heartburn be attributed to GER? The Montreal Consensus has defined GERD as "a condition which develops when the reflux of stomach contents causes troublesome symptoms and/or complications." 66 In the absence of a formal definition for post-POEM GER in the literature, can the Montreal definition be applied? This is debatable.

A large percentage of post-POEM patients do not report any symptoms. The major evidence in favor of GER in these patients emerges from the abnormal EAE, the reported incidence of which has varied between 0 and $58 \%$ (-Table 2). ${ }^{31,32}$ However, can all pH abnormalities in achalasia be attributed to GER?

It is well known that a large percentage of achalasia patients report GER symptoms or abnormal acid exposure time (AET) even before treatment. Not all these $\mathrm{pH}$ abnormalities can be attributed to GER alone, but can occur due to fermentation of food in the obstructed esophagus. ${ }^{67-69}$ This distinction is highly relevant in the context of GER, and can be identified on manual examination of the $\mathrm{pH}$ tracings. ${ }^{67-69}$ Two patterns of abnormal AET have been identified: (1) a sharp drop in $\mathrm{pH}$ to less than 3 and slow clearance, which is typical of true GER; or (2) a slow drop in $\mathrm{pH}$, rarely dropping below $\mathrm{pH}$ 3.7, which is typical of fermentation secondary to food stasis. ${ }^{69-71}$ If this distinction is not clarified, a large number of patients can be erroneously labeled as GER.

Stasis and fermentation may persist even after treatment of achalasia, and unless the $\mathrm{pH}$ tracings are evaluated manually, many of these patients may get misclassified as GER. ${ }^{70}$ Crookes et al reported that 5/20 (25\%) of achalasia patients had an abnormal pretreatment AET based on the automated $\mathrm{pH}$ report; however, on manual reevaluation, fermentation was identified as the cause in $4 / 5$ (80\%) patients. ${ }^{71}$ Furthermore, post LHM, abnormal AET persisted in $6 / 12$ (50\%) patients, of which $3 / 6$ (50\%) were confirmed to be due to fermentation. ${ }^{71}$

Studies evaluating post-POEM GER either have reported variable criteria for assessing GER, especially cutoff values for AET of 4 to $5 \%$ for $\mathrm{pH}<4$ or a DeMeester score $>14.72$ or have not reported them at all. ${ }^{72}$ These values may be relevant to diagnose GER in nonachalasia situations; but they cannot differentiate between true GER and fermentation and can therefore lead to confusion regarding assessment of true post-POEM GER. It has therefore been recommended that either manual evaluation of the $\mathrm{pH}$ tracings be performed or a cutoff value of $\mathrm{AET}<2.9 \%$ for $\mathrm{pH}<3$ be used on an automated tracing for diagnosis of true postmyotomy GER by any approach. ${ }^{71}$

Can GER be documented in all symptomatic patients? This too is unclear. Ponds et al-in their case-control study that investigated mechanisms underlying reflux symptoms in treated achalasia patients by analyzing esophageal function, acidification patterns, and symptom perception-reported that reflux symptoms in treated achalasia patients were rarely caused by GER, and most instances of esophageal acidification were not related to reflux. Instead, esophageal hypersensitivity to chemical and mechanical stimuli was a possible factor responsible for symptom generation. ${ }^{65}$

Recently, the Lyon Consensus criteria were defined to identify and address the controversies surrounding conclusive diagnosis of GER in several clinical situations. ${ }^{73}$ The consensus published the following criteria for diagnosis of GER: (1) conclusive diagnosis of GER can be entertained if AET $>6 \%$ or there is presence of LA (Los Angeles) grade C/D esophagitis, long segment Barrett's, or a peptic stricture; (2) strong evidence against GERD can be confirmed if patients report $\mathrm{AET}<4 \%$ or have a normal endoscopy; or (3) the evaluation may be inconclusive for GERD when AET ranges between 4 and $6 \%$ or there is presence of LA grade $A / B$ esophagitis. For the third criterion, it is recommended that additional factors-histopathology, low mucosal impedance, reflux-symptom association $>80 \%$ on impedance $\mathrm{pH}$, hypotensive LES, hiatus hernia, or esophageal hypomotility-be implemented to confirm or refute the diagnosis. ${ }^{73,74}$ The importance of the Lyon Consensus lies in the fact that it identifies and takes into consideration the limitations of the current evaluation methods for GER. It is therefore important that post-POEM GER be measured using this yardstick. ${ }^{72}$

It is well known that majority of post-POEM patients are asymptomatic, have borderline abnormal $\mathrm{pH}$ studies, and may have no or mild grade A or B esophagitis on endoscopy. ${ }^{9,13,16,25,31}$ It is possible that many of these patients do not have true GER but these findings are a result of fermentation. $^{75}$

In view of these findings, a revised and more objective definition for post-POEM GER based on the Lyon Consensus guidelines can be considered as follows: "a condition developing in a patient post POEM that presents with symptomatic or asymptomatic GER documented by AET $>6 \%$ on $\mathrm{pH}$ studies or endoscopic evidence of grade C or D esophagitis, peptic stricture, or long segment Barrett's." All other patients who fail to meet these criteria require additional evaluation to confirm or refute the presence of GER.

When is the best time to evaluate for post-POEM GER? Although studies have reported more than one evaluation at $1,3,6$, and 12 months post-POEM, it is recommended to evaluate the patient sometime between 3 and 6 months postPOEM and that these evaluations (especially $\mathrm{pH}$ studies) be performed with the patient off PPI for 4 to 6 weeks. ${ }^{72}$

Recently, Modayil et al proposed an alternative explanation for solitary GEJ ulcers seen on follow-up esophagogastro-duodenoscopy (EGD) after POEM. ${ }^{76}$ The appearance of these ulcers is different from that of erosive esophagitis. They hypothesized that such solitary ulcers are more likely to be ischemic in nature because of mucosal ischemia secondary to the submucosal tunnel, rather than because of true erosive esophagitis. The argument in support of this hypothesis is that patients with ischemic ulcers had normal $\mathrm{pH}$ 
readings as compared with those with esophagitis wherein $\mathrm{pH}$ studies were abnormal in favor of GER. Although these findings require substantiation by additional studies, this hypothesis highlights the controversies and limitations regarding objective endoscopic assessment of post-POEM GER.

\section{Treatment of Post-POEM GER}

Majority of patients respond to standard PPI therapy. ${ }^{26,49,72}$ Nabi et al reported complete resolution of erosive esophagitis in $81 \%$ of patients after PPI therapy. ${ }^{26}$ Repici et al reported a wide range of PPI usage after POEM between 2.6 and $27.8 \% .{ }^{25}$ However, significant discrepancy has been reported between clinical symptoms of GER, objective $\mathrm{pH}$ studies, and endoscopic esophagitis. ${ }^{20,25,77}$ Furthermore, pH positivity and endoscopic esophagitis rates are usually higher than symptomatic GER after POEM. This raises the question whether PPI usage is directed primarily toward symptom resolution or toward healing of the esophagitis. ${ }^{34,49}$ How long to prescribe PPI post POEM is another controversial issue. Most recent guidelines recommend PPI usage for at least 2 years post POEM. ${ }^{49,72}$ PPI usage beyond 2 years has not been studied in the context of post-POEM GER. Longterm risks must be carefully weighed against the benefits and protection that PPIs may offer against GER complications. Until then, it may be reasonable to continue long-term PPIs only for patients with persistent troublesome symptoms beyond 2 years, those reporting GER complications such as stricture or Barrett's, or in those patients wherein the diagnosis of post-POEM GER has been unequivocally documented based on the recommended evaluation algorithm (-Fig. 3).

GER-related AEs have been rare after POEM. Three documented cases of GER-related strictures were all treated by dilatation and long-term PPI therapy. ${ }^{10,78}$ Histologically confirmed Barrett's has been reported in three patients, although one of these patients had pre-existing Barrett's prior to POEM that was possibly related to stasis esophagitis. ${ }^{78}$ A case of post-POEM Barrett's cancer has also been reported. ${ }^{79}$ Refractory post-POEM GER not responding to PPI is generally uncommon. ${ }^{49,72,80}$

Antireflux procedures (ARPs) have occasionally been reported for patients with refractory GER symptoms. Second-stage transoral incisionless fundoplication for symptomatic post-POEM GERD has been reported in five patients. All patients could discontinue PPI at a mean of 27 months of follow-up. ${ }^{81,82}$ There have been few case reports of subsequent laparoscopic fundoplication following POEM. $^{49}$

Inoue et al reported safety and feasibility of a novel endoscopic partial fundoplication performed in conjunction with POEM $(\mathrm{POEM}+\mathrm{F})$ as a potential minimally invasive option to prevent post-POEM GER. ${ }^{83}$ The procedure involves performing a standard anterior full-thickness POEM at the 12 o'clock position followed by entry into the peritoneal cavity by dissecting and opening the overlying serosa over the gastric myotomy. The gastric fundus is folded and fixed to the distal end of the myotomy using endoclips and endoloop to create a partial wrap. At 3-month follow-up, an intact wrap was demonstrated in 19/21 patients. Conceptually, $\mathrm{POEM}+\mathrm{F}$ comes closest to the Dor fundoplication that is conventionally performed following LHM. Therefore, it will be interesting to review these results in the long term. Results of $\mathrm{POEM}+\mathrm{F}$ have also been evaluated at 1-year follow-up in a single arm study published from the authors' group. Wrap integrity was confirmed in $82.6 \%$ and GER was identified in only $11.1 \%$ patients at a median 1 -year followup, much lower than that reported for most POEM studies. ${ }^{75}$ Another short case series from the authors' group described technical variations to simplify the originally described

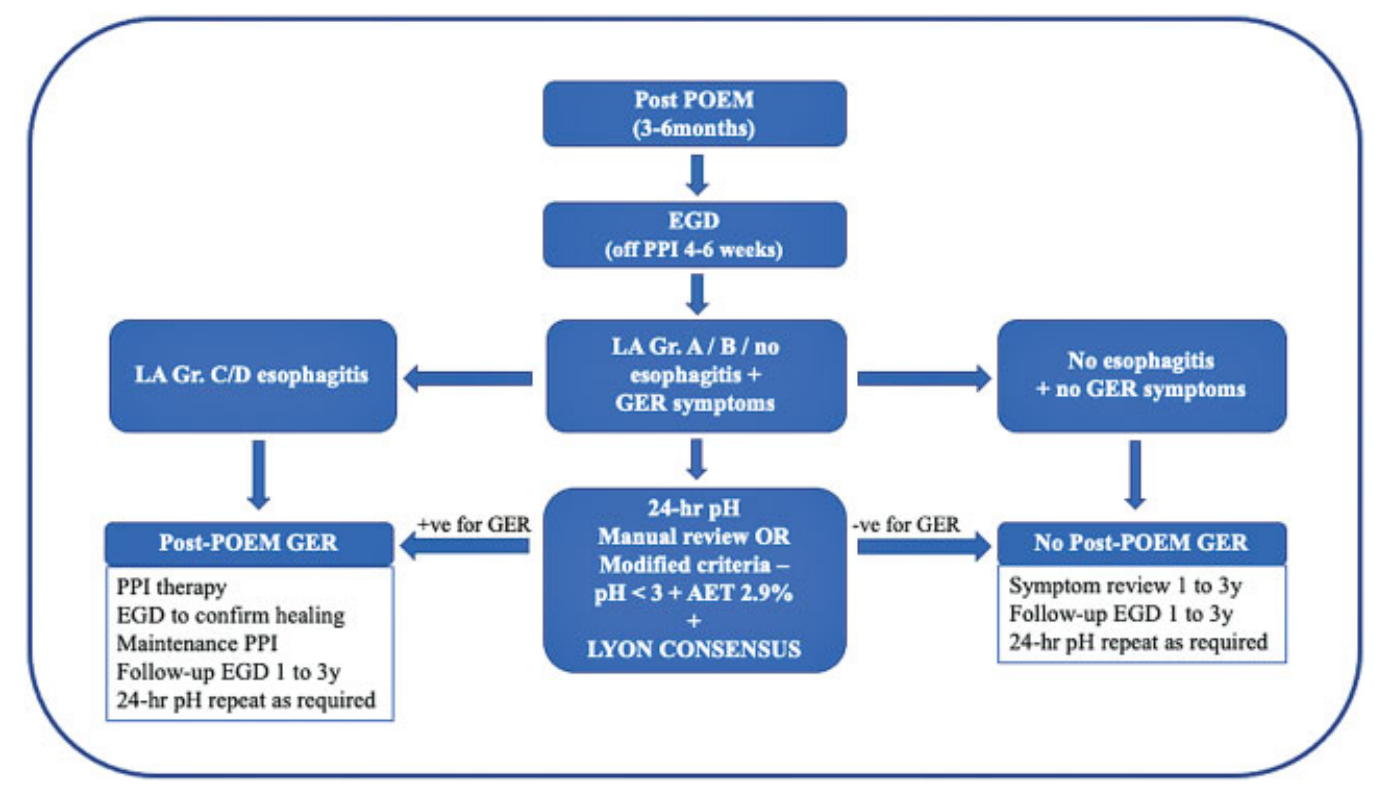

Fig. 3 Recommended clinical algorithm for evaluation and management of post-POEM GER. (Adapted and modified from Bechara et al ${ }^{72}$; and based on the Lyon Consensus criteria. ${ }^{73}$ ) Follow-up EGD every $1-3$ years is recommended irrespective of GER symptoms to screen for squamous cell carcinoma. 
procedure, which has demonstrated a short learning curve. $^{75,84}$ Inoue and co-workers have also described a second session fundoplication (POEF) using a suturing technique for wrap anchoring instead of the endoloop and clips performed 6 months after a posterior POEM. ${ }^{85}$

Data on fundoplication techniques are gradually emerging. Long-term data are required to determine which of these techniques can offer long-lasting relief for post-POEM GER. Another unanswered question is whether these procedures should be performed prophylactically after every POEM as in the case of LHM (although this itself is controversial), or whether they should be reserved for refractory patients during follow-up. Further studies are required to address this controversy.

\section{Implications for Clinical Practice}

What inferences can a clinician draw from the earlier discussion?

It appears that GER is an inevitable consequence of any treatment modality for AC, especially LHM and POEM. The difference between GER following $\mathrm{LHM} \pm \mathrm{F}$ and that after POEM is that post-POEM GER, although more frequent initially, often stabilizes and reduces with time, whereas that after $\mathrm{LHM} \pm \mathrm{F}$ may progressively increase during follow-up. ${ }^{76} \mathrm{AC}$ patients must be counseled regarding these potential risks of GER and its long-term consequences before subjecting them to myotomy. Presently, no definite preoperative predictors for post-POEM GER have been identified. While performing POEM, endoscopists must observe two important technical aspects that impact post-POEM GER: (1) maintaining length gastric myotomy less than $2 \mathrm{~cm}$ and (2) preventing injury to the sling fibers of the LES during myotomy.

Most post-POEM GER occurs during the early post-POEM period and the incidence plateaus at about 2 years. Prophylactic PPI can therefore be recommended for 2 years postPOEM for all patients. ${ }^{2}$

At the same time, it is important to remember that evaluation of post-POEM GER is a complex process requiring a combined assessment of symptoms, EGD findings, and $\mathrm{pH}$ studies. EGD should preferably performed with the patient off PPI for 4 to 6 weeks to optimally assess for endoscopic evidence of esophagitis. ${ }^{72}$ It is important to remember that a significant percentage of patients do not have any GER symptoms, and furthermore, not all symptomatic patients have conclusive GER either. The Lyon Consensus guidelines must be followed for GER diagnosis to prevent overestimation of GER. ${ }^{73} \mathrm{pH}$ tracings must be manually reviewed to differentiate from EAE abnormalities due to fermentation; and if this is not feasible, cutoff values of AET and $\mathrm{pH}$ should be adjusted accordingly. ${ }^{72}$ Post-POEM GER should only be confirmed when endoscopy demonstrates severe grade $\mathrm{C}$ or D esophagitis, or when pH studies are conclusive for GER. Patients with documented GER should be prescribed longterm (possibly lifelong) PPI and should be monitored for delayed AEs related to GER and also for AEs related to longterm PPI use. Patients refractory to PPI therapy can be subjected to suitable ARPs. Primary ARPs at the time of POEM are not currently recommended.

Patients with borderline GER-those with symptoms but no or mild grade A or B esophagitis-should not be labeled as GER but require further evaluation by: (1) esophageal manometry to diagnose residual LES spasm, failed myotomy, or AC recurrence; (2) timed barium swallow to estimate distal esophageal clearance; and/or (3) impedance pH studies to differentiate between true GER and fermentation or other forms of esophageal mucosal hypersensitivity, which may masquerade as GER, as well as additional investigations as may be deemed necessary. ${ }^{73}$

All post-POEM patients require follow-up EGD at 1 to 3 years to evaluate for GER and related AEs and also to screen for squamous cell carcinoma, which can develop within longstanding AC. ${ }^{2,72}$ A simplified algorithm for post-POEM follow-up evaluation and management is provided in - Fig. 3 .

\section{Conclusions and Future Directions}

Post-POEM GER is a contentious issue with no clear answers. Despite a century of progress in the treatment of AC, confusion still reigns regarding several aspects of this complex disease entity. One definite conclusion that one can draw from the present discussion is that GER can occur after any type of myotomy for AC, and that based on current evidence, it is more frequent after POEM than after $\mathrm{LHM}+\mathrm{F}$. At the same time, it is equally important to acknowledge that current techniques to diagnose post-POEM GER are inadequate and have limited accuracy. A major challenge for future research would be to devise suitable methods to diagnose postoperative (especially post-POEM) GER. consistently and accurately.

Abnormal EAE can be identified even in untreated AC patients that can persist even posttreatment in half of the patients. More often than not, this abnormal EAE is not true GER but is the result of food fermentation. Accurate and timely differentiation between these two possibilities is required to tailor suitable therapy. The Lyon Consensus currently provides the most objective criteria for conclusive diagnosis of GER and to prevent overdiagnosis, and is recommended to be used in these cases.

Most post-POEM GER is asymptomatic, mild, and easily treatable with PPI, although long-term clinical implications of asymptomatic GER are currently unknown. Future treatment algorithms must design and incorporate suitable strategies and should also define the exact role of ARP in these patients. ARPs, endoscopic or surgical, may be required for those patients who are refractory to PPI therapy. The controversy surrounding routine postmyotomy fundoplication remains and, in the context of POEM, becomes even more relevant given that most GER is mild and PPIresponsive, and endoscopic antireflux modalities are still new and evolving.

As technique of POEM further evolves, it is possible that additional technical modifications that protect naturally existing antireflux mechanisms may be devised and 
implemented. Time will tell if and how these modifications will impact incidence of post-POEM GER in future.

Until such a time, however, prudence demands that we acknowledge, reflect, and accept the solitary reality of a century-long progress of AC treatment-"ensuring critical balance of LES competence during myotomy is the single most vital factor impacting incidence of post-POEM GER." As one could say, while sifting through the haystack of confusion regarding this contentious clinical issue, it is heartening to note that this one consensus has stayed resolute throughout this centenary evolution.

\section{Conflict of Interest}

None declared.

\section{References}

1 Inoue $\mathrm{H}$, Minami $\mathrm{H}$, Kobayashi $\mathrm{Y}$, et al. Peroral endoscopic myotomy (POEM) for esophageal achalasia. Endoscopy 2010;42 (04):265-271

2 Bapaye A, Korrapati SK, Dharamsi S, Dubale N. Third space endoscopy: lessons learnt from a decade of submucosal endoscopy. J Clin Gastroenterol 2020;54(02):114-129

3 von Renteln D, Inoue $\mathrm{H}$, Minami $\mathrm{H}$, et al. Peroral endoscopic myotomy for the treatment of achalasia: a prospective single center study. Am J Gastroenterol 2012;107(03):411-417

4 Stavropoulos SN, Modayil RJ, Friedel D, Savides T. The International Per Oral Endoscopic Myotomy Survey (IPOEMS): a snapshot of the global POEM experience. Surg Endosc 2013;27(09): 3322-3338

5 Onimaru M, Inoue H, Ikeda $\mathrm{H}$, et al. Peroral endoscopic myotomy is a viable option for failed surgical esophagocardiomyotomy instead of redo surgical Heller myotomy: a single center prospective study. J Am Coll Surg 2013;217(04):598-605

6 Ling TS, Guo HM, Yang T, Peng CY, Zou XP, Shi RH. Effectiveness of peroral endoscopic myotomy in the treatment of achalasia: a pilot trial in Chinese Han population with a minimum of one-year follow-up. J Dig Dis 2014;15(07):352-358

7 Sharata A, Kurian AA, Dunst CM, Bhayani NH, Reavis KM, Swanstrom LL. Technique of per-oral endoscopic myotomy (POEM) of the esophagus (with video). Surg Endosc 2014;28(04):1333

8 Inoue $\mathrm{H}$, Sato $\mathrm{H}$, Ikeda $\mathrm{H}$, et al. Per-oral endoscopic myotomy: a series of 500 patients. J Am Coll Surg 2015;221(02):256-264

9 Familiari P, Greco S, Gigante G, et al. Gastroesophageal reflux disease after peroral endoscopic myotomy: analysis of clinical, procedural and functional factors, associated with gastroesophageal reflux disease and esophagitis. Dig Endosc 2016;28(01): 33-41

10 Hungness ES, Sternbach JM, Teitelbaum EN, Kahrilas PJ, Pandolfino JE, Soper NJ. Per-oral endoscopic myotomy (POEM) after the learning curve: durable long-term results with a low complication rate. Ann Surg 2016;264(03):508-517

11 Ramchandani M, Nageshwar Reddy D, Darisetty S, et al. Peroral endoscopic myotomy for achalasia cardia: treatment analysis and follow up of over 200 consecutive patients at a single center. Dig Endosc 2016;28(01):19-26

12 Shiwaku $\mathrm{H}$, Inoue $\mathrm{H}$, Sasaki $\mathrm{T}$, et al. A prospective analysis of GERD after POEM on anterior myotomy. Surg Endosc 2016;30(06): 2496-2504

13 Kumbhari V, Familiari P, Bjerregaard NC, et al. Gastroesophageal reflux after peroral endoscopic myotomy: a multicenter casecontrol study. Endoscopy 2017;49(07):634-642

14 Nabi Z, Ramchandani M, Chavan R, et al. Per-oral endoscopic myotomy for achalasia cardia: outcomes in over 400 consecutive patients. Endosc Int Open 2017;5(05):E331-E339
15 Li Q-L, Wu Q-N, Zhang X-C, et al. Outcomes of per-oral endoscopic myotomy for treatment of esophageal achalasia with a median follow-up of 49 months. Gastrointest Endosc 2018;87(06): 1405-1412.e3

16 Werner YB, Hakanson B, Martinek J, et al. Endoscopic or surgical myotomy in patients with idiopathic achalasia. N Engl J Med 2019;381(23):2219-2229

17 Shiwaku $\mathrm{H}$, Inoue $\mathrm{H}$, Onimaru $\mathrm{M}$, et al. Multicenter collaborative retrospective evaluation of peroral endoscopic myotomy for esophageal achalasia: analysis of data from more than 1300 patients at eight facilities in Japan. Surg Endosc 2020;34(01): 464-468

18 Ponds FA, Fockens P, Lei A, et al. Effect of peroral endoscopic myotomy vs pneumatic dilation on symptom severity and treatment outcomes among treatment-naive patients with achalasia: a randomized clinical trial. JAMA 2019;322(02):134-144

19 Teitelbaum EN, Dunst CM, Reavis KM, et al. Clinical outcomes five years after POEM for treatment of primary esophageal motility disorders. Surg Endosc 2018;32(01):421-427

20 Schlottmann F, Luckett DJ, Fine J, Shaheen NJ, Patti MG. Laparoscopic Heller myotomy versus peroral endoscopic myotomy (POEM) for achalasia: a systematic review and meta-analysis. Ann Surg 2018;267(03):451-460

21 Martinek J, Svecova H, Vackova Z, et al. Per-oral endoscopic myotomy (POEM): mid-term efficacy and safety. Surg Endosc 2018;32(03):1293-1302

22 Aiolfi A, Bona D, Riva CG, et al. Systematic review and bayesian network meta-analysis comparing laparoscopic Heller myotomy, pneumatic dilatation, and peroral endoscopic myotomy for esophageal achalasia. J Laparoendosc Adv Surg Tech A 2020;30 (02):147-155

23 Arevalo G, Sippey M, Martin-Del-Campo LA, He J, Ali A, Marks J. Post-POEM reflux: who's at risk? Surg Endosc 2020;34(07): 3163-3168

24 Rösch T, Repici A, Boeckxstaens G. Will reflux kill POEM? Endoscopy 2017;49(07):625-628

25 Repici A, Fuccio L, Maselli R, et al. GERD after per-oral endoscopic myotomy as compared with Heller's myotomy with fundoplication: a systematic review with meta-analysis. Gastrointest Endosc 2018;87(04):934-943.e18

26 Nabi Z, Ramchandani M, Kotla R, et al. Gastroesophageal reflux disease after peroral endoscopic myotomy is unpredictable, but responsive to proton pump inhibitor therapy: a large, singlecenter study. Endoscopy 2020;52(08):643-651

27 Sharata AM, Dunst CM, Pescarus R, et al. Peroral endoscopic myotomy (POEM) for esophageal primary motility disorders: analysis of 100 consecutive patients. J Gastrointest Surg 2015; 19(01):161-170, discussion 170

28 Sanaka MR, Thota PN, Parikh MP, et al. Peroral endoscopic myotomy leads to higher rates of abnormal esophageal acid exposure than laparoscopic Heller myotomy in achalasia. Surg Endosc 2019;33(07):2284-2292

29 Ramirez M, Zubieta C, Ciotola F, et al. Per oral endoscopic myotomy vs. laparoscopic Heller myotomy, does gastric extension length matter? Surg Endosc 2018;32(01):282-288

30 Olson MT, Triantafyllou T, Singhal S. A decade of investigation: peroral endoscopic myotomy versus laparoscopic Heller myotomy for achalasia. J Laparoendosc Adv Surg Tech A 2019;29(09):1093-1104

31 Jones EL, Meara MP, Schwartz JS, Hazey JW, Perry KA. Gastroesophageal reflux symptoms do not correlate with objective $\mathrm{pH}$ testing after peroral endoscopic myotomy. Surg Endosc 2016;30 (03):947-952

32 Lu B, Li M, Hu Y, Xu Y, Zhang S, Cai LJ. Effect of peroral esophageal myotomy for achalasia treatment: a Chinese study. World J Gastroenterol 2015;21(18):5622-5629

33 Shiwaku $\mathrm{H}$, Inoue $\mathrm{H}$, Sato $\mathrm{H}$, et al. Peroral endoscopicmyotomy for achalasia: a prospective multicenter study in Japan. Gastrointest Endosc 2020;91(05):1037-1044.e2 
34 Hernández-Mondragón OV, Solórzano-Pineda OM, GonzálezMartínez M, Blancas-Valencia JM. Gastroesophageal reflux disease after peroral endoscopic myotomy: short-term, mediumterm, and long-term results. Rev Gastroenterol Mex (Engl Ed) 2020;85(01):4-11

35 Isomoto H, Ikebuchi Y. Japanese guidelines for peroral endoscopic myotomy: 1st edition. Dig Endosc 2019;31(01):27-29

36 Ellis F, Cole FL. Reflux after cardiomyotomy. Gut 1965;6:80-84

37 Andreollo NA, Earlam RJ. Heller's myotomy for achalasia: is an added anti-reflux procedure necessary? Br J Surg 1987;74(09): 765-769

38 Heller E. Extramukose Kardioplastik beim chronischen Kardiospasmus mil Dilatation des Oesophagus. Mitt Grenzgeb Med Chir 1914;27:141-149

39 Zaaijer JH. Cardiospasm in the aged. Ann Surg 1923;77(05): 615-617

40 Earlam RJ, Ellis FH Jr, Nobrega FT. Achalasia of the esophagus in a small urban community. Mayo Clin Proc 1969;44(07):478-483

41 Spiess AE, Kahrilas PJ. Treating achalasia: from whalebone to laparoscope. JAMA 1998;280(07):638-642

42 Torquati A, Lutfi R, Khaitan L, Sharp KW, Richards WO. Heller myotomy vs Heller myotomy plus Dor fundoplication: cost-utility analysis of a randomized trial. Surg Endosc 2006;20(03):389-393

43 Kumagai K, Kjellin A, Tsai JA, et al. Toupet versus Dor as a procedure to prevent reflux after cardiomyotomy for achalasia: results of a randomised clinical trial. Int J Surg 2014;12(07): 673-680

44 Rawlings A, Soper NJ, Oelschlager B, et al. Laparoscopic Dor versus Toupet fundoplication following Heller myotomy for achalasia: results of a multicenter, prospective, randomized-controlled trial. Surg Endosc 2012;26(01):18-26

45 Boeckxstaens GE, Annese V, des Varannes SB, et al;European Achalasia Trial Investigators. Pneumatic dilation versus laparoscopic Heller's myotomy for idiopathic achalasia. N Engl J Med 2011;364(19):1807-1816

46 Csendes A, Braghetto I, Burdiles P, Korn O, Csendes P, Henríquez A. Very late results of esophagomyotomy for patients with achalasia: clinical, endoscopic, histologic, manometric, and acid reflux studies in 67 patients for a mean follow-up of 190 months. Ann Surg 2006;243(02):196-203

47 Popoff AM, Myers JA, Zelhart M, et al. Long-term symptom relief and patient satisfaction after Heller myotomy and Toupet fundoplication for achalasia. Am J Surg 2012;203(03):339-342, discussion 342

48 Simić AP, Radovanović NS, Skrobić OM, Raznatović ZJ, Pesko PM. Significance of limited hiatal dissection in surgery for achalasia. J Gastrointest Surg 2010;14(04):587-593

49 Inoue $\mathrm{H}$, Shiwaku $\mathrm{H}$, Kobayashi $\mathrm{Y}$, et al. Statement for gastroesophageal reflux disease after peroral endoscopic myotomy from an international multicenter experience. Esophagus 2020; 17(01):3-10

50 Baldaque-Silva F, Marques M, Vilas-Boas F, Maia JD, Sá F, Macedo G. New transillumination auxiliary technique for peroral endoscopic myotomy. Gastrointest Endosc 2014;79(04):544-545

51 Grimes KL, Inoue H, Onimaru M, et al. Double-scope per oral endoscopic myotomy (POEM): a prospective randomized controlled trial. Surg Endosc 2016;30(04):1344-1351

52 Zaninotto G, Bennett C, Boeckxstaens G, et al. The 2018 ISDE achalasia guidelines. Dis Esophagus 2018;31(09):

53 Inoue $\mathrm{H}$, Shiwaku $\mathrm{H}$, Iwakiri K, et al. Clinical practice guidelines for peroral endoscopic myotomy. Dig Endosc 2018;30(05):563-579

54 Grimes KL, Bechara R, Shimamura Y, Ikeda H, Inoue H. Gastric myotomy length affects severity but not rate of post-procedure reflux: 3-year follow-up of a prospective randomized controlled trial of double-scope per-oral endoscopic myotomy (POEM) for esophageal achalasia. Surg Endosc 2020;34(07):2963-2968

55 Tanaka S, Toyonaga T, Kawara F, et al. Novel per-oral endoscopic myotomy method preserving oblique muscle using two penetrat- ing vessels as anatomic landmarks reduces postoperative gastroesophageal reflux. J Gastroenterol Hepatol 2019;34(12): 2158-2163

56 Tanaka S, Kawara F, Toyonaga T, et al. Two penetrating vessels as a novel indicator of the appropriate distal end of peroral endoscopic myotomy. Dig Endosc 2018;30(02):206-211

57 Stavropoulos SN, Zhang X, Islam S, et al. Sa1227 The "Anti-Reflux" POEM: A Technique Modification That Drastically Reduces Objectively Measured Reflux After Per Oral Endoscopic Myotomy (POEM). Gastrointest Endosc 2020;91(06):AB119

58 Ramchandani M, Nabi Z, Reddy DN, et al. Outcomes of anterior myotomy versus posterior myotomy during POEM: a randomized pilot study. Endosc Int Open 2018;6(02):E190-E198

59 Khashab MA, Sanaei O, Rivory J, et al. Peroral endoscopic myotomy: anterior versus posterior approach: a randomized singleblinded clinical trial. Gastrointest Endosc 2020;91(02):288-297. e7

60 Wang XH, Tan YY, Zhu HY, Li CJ, Liu DL. Full-thickness myotomy is associated with higher rate of postoperative gastroesophageal reflux disease. World J Gastroenterol 2016;22(42):9419-9426

61 Li C, Gong A, Zhang J, et al. Clinical outcomes and safety of partial full-thickness myotomy versus circular muscle myotomy in peroral endoscopic myotomy for achalasia patients. Gastroenterol Res Pract 2017;2017:2676513

62 Li QL, Chen WF, Zhou PH, et al. Peroral endoscopic myotomy for the treatment of achalasia: a clinical comparative study of endoscopic full-thickness and circular muscle myotomy. J Am Coll Surg 2013;217(03):442-451

63 Teitelbaum EN, Soper NJ, Pandolfino JE, et al. Esophagogastric junction distensibility measurements during Heller myotomy and POEM for achalasia predict postoperative symptomatic outcomes. Surg Endosc 2015;29(03):522-528

64 Teitelbaum EN, Sternbach JM, El Khoury R, et al. The effect of incremental distal gastric myotomy lengths on EGJ distensibility during POEM for achalasia. Surg Endosc 2016;30(02):745-750

65 Ponds FA, Oors JM, Smout AJPM, Bredenoord AJ. Reflux symptoms and oesophageal acidification in treated achalasia patients are often not reflux related. Gut 2021;70(01):30-39

66 Vakil N, van Zanten SV, Kahrilas P, Dent J, Jones RGlobal Consensus Group. The Montreal definition and classification of gastroesophageal reflux disease: a global evidence-based consensus. Am J Gastroenterol 2006;101(08):1900-1920, quiz 1943

67 Shoenut JP, Duerksen D, Yaffe CS. A prospective assessment of gastroesophageal reflux before and after treatment of achalasia patients: pneumatic dilation versus transthoracic limited myotomy. Am J Gastroenterol 1997;92(07):1109-1112

68 Fisichella PM, Raz D, Palazzo F, Niponmick I, Patti MG. Clinical, radiological, and manometric profile in 145 patients with untreated achalasia. World J Surg 2008;32(09):1974-1979

69 Shoenut JP, Micflikier AB, Yaffe CS, Den Boer B, Teskey JM. Reflux in untreated achalasia patients. J Clin Gastroenterol 1995;20(01): 6-11

70 Smart HL, Foster PN, Evans DF, Slevin B, Atkinson M. Twenty four hour oesophageal acidity in achalasia before and after pneumatic dilatation. Gut 1987;28(07):883-887

71 Crookes PF, Corkill S, DeMeester TR. Gastroesophageal reflux in achalasia. When is reflux really reflux? Dig Dis Sci 1997;42(07): 1354-1361

72 Bechara R, Inoue H, Shimamura Y, Reed D. Gastroesophageal reflux disease after peroral endoscopic myotomy: lest we forget what we already know. Dis Esophagus 2019;32(12):doz106

73 Gyawali CP, Kahrilas PJ, Savarino E, et al. Modern diagnosis of GERD: the Lyon Consensus. Gut 2018;67(07):1351-1362

74 Roman S, Gyawali CP, Savarino E, et al;GERD consensus group. Ambulatory reflux monitoring for diagnosis of gastro-esophageal reflux disease: update of the Porto consensus and recommendations from an international consensus group. Neurogastroenterol Motil 2017;29(10):1-15 
75 Bapaye A, Dashatwar P, Dharamsi S, Pujari R, Gadhikar H. Singlesession endoscopic fundoplication after peroral endoscopic myotomy $(\mathrm{POEM}+\mathrm{F})$ for prevention of post gastroesophageal reflux - 1year follow-up study. Endoscopy 2021;53(11):1114-1121

76 Modayil RJ, Zhang X, Rothberg B, et al. Peroral endoscopic myotomy: 10-year outcomes from a large, single-center U.S. series with high follow-up completion and comprehensive analysis of long-term efficacy, safety, objective GERD, and endoscopic functional luminal assessment. Gastrointest Endosc 2021;94(05): 930-942

77 Akintoye E, Kumar N, Obaitan I, Alayo QA, Thompson CC. Peroral endoscopic myotomy: a meta-analysis. Endoscopy 2016;48(12): 1059-1068

78 Werner YB, Costamagna G, Swanström LL, et al. Clinical response to peroral endoscopic myotomy in patients with idiopathic achalasia at a minimum follow-up of 2 years. Gut 2016;65(06): 899-906

79 Ichkhanian Y, Benias P, Khashab MA. Case of early Barrett cancer following peroral endoscopic myotomy. Gut 2019;68(12):2107-2110
80 Swanström LL. POEM: the sun rises in the East.... Gastrointest Endosc 2018;87(06):1413-1414

81 Tyberg A, Choi A, Gaidhane M, Kahaleh M. Transoral incisional fundoplication for reflux after peroral endoscopic myotomy: a crucial addition to our arsenal. Endosc Int Open 2018;6(05): E549-E552

82 Kumta NA, Kedia P, Sethi A, Kahaleh M. Transoral incisionless fundoplication for treatment of refractory GERD after peroral endoscopic myotomy. Gastrointest Endosc 2015;81(01):224-225

83 Inoue $\mathrm{H}$, Ueno A, Shimamura Y, et al. Peroral endoscopic myotomy and fundoplication: a novel NOTES procedure. Endoscopy 2019; 51(02):161-164

84 Bapaye A, Dharamsi S, Jain R, et al. Concomitant endoscopic fundoplication - can it reduce the risk of gastroesophageal reflux following peroral endoscopic myotomy? Endoscopy 2020;52(02): E73-E74

85 Toshimori A, Inoue $\mathrm{H}$, Shimamura Y, Abad MRA, Onimaru M. Peroral endoscopic fundoplication: a brand-new intervention for GERD. VideoGIE 2020;5(06):244-246 